\title{
Association of Aeromonas spp. with travellers' diarrhoea in Finland
}

\author{
M. L. HÄNNINEN, S. SALMI, L. MATTILA*, R. TAIPALINEN* and A. SIITONEN* \\ Department of Food and Environmental Hygiene, College of Veterinary Medicine, PO Box 6, FIN-00581, Helsinki \\ and "Laboratory of Enteric Pathogens, National Public Health Institute, Mannerheimint. 166, Helsinki, Finland
}

\begin{abstract}
Summary. The association of Aeromonas spp. with travellers' diarrhoea was studied among 978 Finnish tourists travelling to Morocco in winter $(n=398)$ and autumn $(n=580)$ in 1989. Fifty-five isolates from diarrhoeal patients with $(\mathrm{n}=16)$ or without $(\mathrm{n}=39)$ a recent travelling history in a developing country were also included. In Morocco, Aeromonas spp. were isolated from $8.7 \%$ of patients with diarrhoea and from $1.4 \%$ of non-diarrhoeal tourists $(\mathrm{p}<0.001)$. Aeromonas spp. were found as the sole pathogen in $5.5 \%$ of patients $(\mathrm{p}<0.001)$. Diarrhoea with multiple pathogens, including Aeromonas spp., was found in $3.1 \%$ of patients. Species identification by phenotypic and genotypic methods indicated that $A$.veronii biotype sobria (hybridisation group HG 8/10) and $A$. caviae (HG 4) were the most common Aeromonas spp. associated with travellers' diarrhoea. A. hydrophila (HG 1) and A. caviae (HG 4) were common in patients acquiring diarrhoea in Finland. Ribotyping of strains within a species showed that all strains had different ribotypes although the tourists were infected during the same trip. This study suggested that only certain Aeromonas spp. were commonly found in travellers' diarrhoea. However, the causative role of those species is unclear.
\end{abstract}

\section{Introduction}

An increasing number of epidemiological studies indicate that Aeromonas spp. may be aetiological agents in sporadic diarrhoeal illness in both developed and developing countries. ${ }^{1-7}$ In developed countries, Aeromonas spp. have been found in $0 \cdot 8-7 \cdot 4 \%$ of stool specimens submitted for examination for enteropathogens. Their prevalence in stool specimens from healthy persons has varied from $0.4 \%$ to $2.1 \%$. In developing countries, the isolation rate from diarrhoeal and control samples seems to be higher than in developed countries. For example, in Thailand, Aeromonas spp. were isolated from $34 \%$ of stools from adult patients with diarrhoea and from $27.5 \%$ of those from healthy controls. ${ }^{8}$ Aeromonas spp. occurred in faecal specimens of Peace Corps workers in Thailand in $30.8 \%$ of episodes of diarrhoea but in only $8.5 \%$ of healthy controls. ${ }^{9}$ These indirect pieces of evidence suggest that Aeromonas spp. may have an aetiological role in travellers' diarrhoea. ${ }^{1,7}$

The assessment of the role of mesophilic Aeromonas spp. in diarrhoeal illness has been hampered by the complicated taxonomy of the species. ${ }^{10}$ At least eight species are described on the basis of phenotypic

Received 26 May 1994; accepted 5 July 1994. characteristics: $A$. hydrophila, $A$. caviae, $A$. media, $A$. eucrenophila, $A$. veronii biotypes sobria and veronii, $A$. jandaei, $A$. schubertii and $A$. trota ${ }^{10,11}$ DNA-DNA hybridisation studies identify 13 genospecies (hybridisation groups, $\mathrm{HGs}){ }^{10,12}$

The aim of the present study was to examine the role of Aeromonas spp. in travellers' diarrhoea in Finnish tourists travelling to Morocco in 1989. Some Aeromonas strains isolated from faecal samples of Finnish subjects with or without a history of recent travel to a developing country were also included. The phenotypic and genotypic characteristics of all isolates were identified carefully.

\section{Materials and methods}

\section{Subjects and faecal specimens}

The Aeromonas data were collected during studies on the aetiology, prevention and treatment of diarrhoea in Finnish tourists travelling to Morocco in $1989 .{ }^{13-15}$ Faecal samples were cultivated from 398 adult travellers in the winter (11 Jan. -8 Feb.) and from 580 adult travellers in the autumn (24 Oct. -21 Nov.). Of these 978 subjects, 389 had received the oral B subunit or whole cell cholera vaccine before the trip in 
a double blind manner. Faecal samples from tourists who had diarrhoea during the trip were investigated in Morocco by Finnish experts at the temporary local laboratory for the common enteric pathogens. ${ }^{15}$ Travellers' diarrhoea was defined as four or more unformed stools within a 24-h period or at least three unformed stools in an 8-h period and at least one of the following additional symptoms: nausea, vomiting, abdominal pain or cramps. ${ }^{3}$

For comparison of possible regional differences in the distribution of Aeromonas spp., all Aeromonas strains that were isolated from diarrhoeal patients and submitted to the Laboratory of Enteric Pathogens, Finland during the years 1986-1989 were included in the study (a total of 55 faecal isolates); 16 were isolated after patients' travel abroad and 39 isolates were from subjects living in the southern part of Finland and without a known history of recent travel abroad.

\section{Isolation and identification of Aeromonas spp.}

Aeromonas spp. were detected on Aeromonas Selective Medium (Difco). Initially, Aeromonas spp. were identified by standard methods by the oxidase test and API 20E (bioMérieux SA, Marcy d'Etoile, France). The selective medium was incubated at $30^{\circ} \mathrm{C}$ and biochemical tests were first done at $37^{\circ} \mathrm{C}$. After isolation the strains were stored in skimmed milk at $-70^{\circ} \mathrm{C}$.

Aeromonas spp. were identified to species level by the criteria of Altwegg et al. ${ }^{1}$ Popoff ${ }^{11}$ and Carnahan et al. ${ }^{16}$ The most important criteria used in their identification were: aesculin hydrolysis; amino acid (arginine, lysine and ornithine) decarboxylation or dehydrogenation; gas production from glucose; acid production from arabinose, sorbitol, saccharose, salicin or rhamnose; acetylmethyl-carbinol production (V-P); elastase production; cephalothin sensitivity and haemolysin production. For the phenotypic identification of the three hybridisation groups (HG 1, HG 2 and HG 3) of $A$. hydrophila, the following methods were used: utilisation of DL-lactate, citrate or urocanic acid as a sole source of carbon and production of acid from sorbitol and rhamnose.12,16 Similarly, for the identification of HG 4, HG 5A and HG 5B (A. caviae), utilisation of DL-lactate or citrate and haemolysis were used. ${ }^{12,17}$ In these identifications, both conventional media and API 20E and ID 32GN were used (bioMérieux).

\section{Genotypic methods}

Ribotyping was used for genetic identification of a genospecies (HG) and for subtyping of strains beyond species level. ${ }^{18}$ Chromosomal DNA was purified by phenol extraction and isopropanol precipitation. ${ }^{19}$ The purity and concentration of DNA were determined spectrophotometrically and in agarose gels. Chromosomal DNA $(2-5 \mu \mathrm{g})$ was digested with restriction endonuclease SmaI under recommended conditions (Boehringer Mannheim, GmbH Mannheim, Germany). DNA from representative strains of A. caviae (HG 4) and A. sobria (HG 8/10) were also digested with $P s t \mathrm{I}$ and $B g l \mathrm{I}$ (Boehringer Mannheim). The digests were analysed in agarose $1.2 \%$ gels (Sea Kem ME agarose, FMC BioProducts, Rockland, USA), with half-strength TBE ( $45 \mathrm{~mm}$ Tris, $1 \mathrm{~mm}$ EDTA, $\mathrm{pH}$ adjusted to 8.0 with boric acid) as running buffer. The DNA was transferred to a positively charged nylon membrane (Hybond ${ }^{\circledR}-\mathrm{N}+$; Amersham International plc) by vacuum-blotting (Vacugene ${ }^{\circledR}$ XL vacuumblotting system; Pharmacia LKB Biotechnology, Uppsala, Sweden). The probe was plasmid pKK3535 harbouring the 5S, 16S, and 23S rRNA genes. The membranes were pre-hybridised for $2 \mathrm{~h}$ and hybridised overnight at $60^{\circ} \mathrm{C}$ in sealed plastic bags. DNA restriction fragments which hybridised with the digoxigenin-labelled probe were detected colorimetrically by alkaline phosphatase-labelled antidigoxigenin as recommended in the DIG DNA Labeling and Detection Kit (Boehringer Mannheim). Reference strains of each hybridisation group were used for comparison of ribotyping patterns.

\section{Statistical analysis}

Fisher's exact test was used when the groups with or without diarrhoea were compared.

\section{Results}

\section{Aeromonas spp. in tourists to Morocco}

Aeromonas spp. were isolated from $32(3.3 \%)$ of 978 adult tourists travelling to Morocco in the winter and autumn of 1989 (fig. 1). Of these, 22 isolates $(8.7 \%)$ were from 254 tourists with diarrhoea $(p<0.001$, compared with 10 isolates from 724 non-diarrhoeal participants). The total isolation frequency in winter $(2 \%)$ did not differ statistically from that of autumn (4\%). In 14 (5.5\%) tourists with diarrhoea, Aeromonas spp. were isolated as the sole pathogen $(\mathrm{p}<0.001$, compared with similar findings in eight tourists without diarrhoea). In 10 tourists with or without diarrhoea, Aeromonas spp. were found in association with some other enteric pathogen (enterotoxigenic Escherichia coli, Campylobacter jejuni or Salmonella enterica serovar Enteritidis) (fig. 1).

$A$. sobria ( $A$. veronii biotype sobria) and $A$. caviae were the most common Aeromonas spp. identified (fig. 2). More than half of $A$. veronii biotype sobria (6 of 11 strains) and $A$. caviae (6 of 10 strains) isolations were from diarrhoeal patients with no other identified pathogens in their stools $(p<0.001$, compared with the corresponding findings in non-diarrhoeal participants) (fig. 2). In the samples from 19 nondiarrhoeal participants, all three common Aeromonas spp.-A. hydrophila (four isolates), A. caviae (two) and 


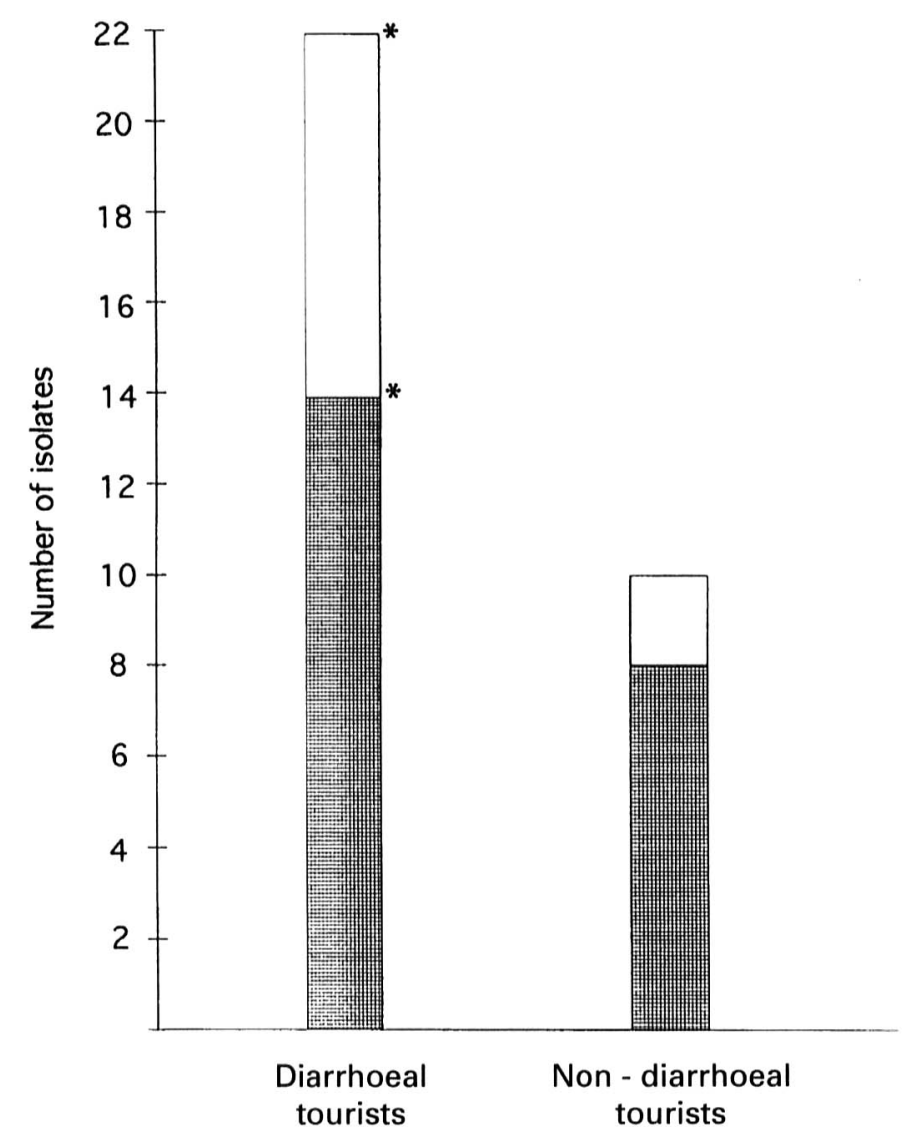

Fig. 1. Aeromonas spp. in faecal samples from 978 adult Finnish tourists who travelled to Morocco in 1989: 罒, sole pathogen isolated; $\square$, with another enteric pathogen; ${ }^{*} \mathrm{p}<0.001$ compared with non-diarrhoeal tourists, Fisher's exact test.

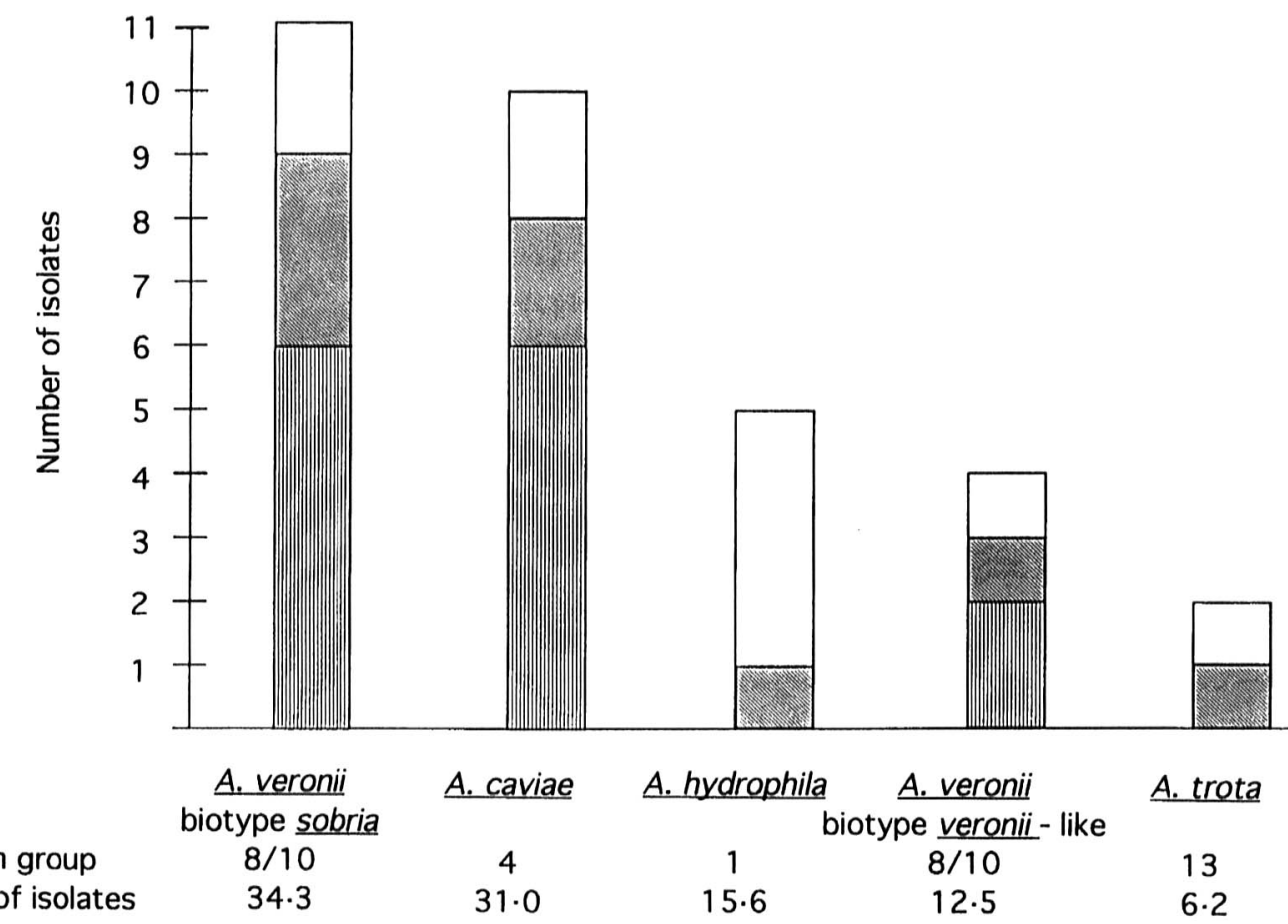

Fig. 2. Distribution of identified Aeromonas spp. and corresponding hybridisation groups in faecal samples from 254 diarrhoeal and 724 nondiarrhoeal ( $\square$ ) Finnish tourists who travelled to Morocco in 1989; 四, diarrhoeal cases with Aeromonas sp. as sole pathogenic isolate; $\mathbb{\$}$, diarrhoeal cases with Aeromonas sp. plus other enteric pathogens.

A. sobria (two)-were isolated. The remaining two isolates were $A$. trota and $A$. veronii biotype veronii.

All patients with Aeromonas spp. as the sole patho- gen had macroscopically watery or slimy diarrhoea lasting 2-20 (mean 5.9) days. Fever, nausea, headache or abdominal pain were present in some patients. No 


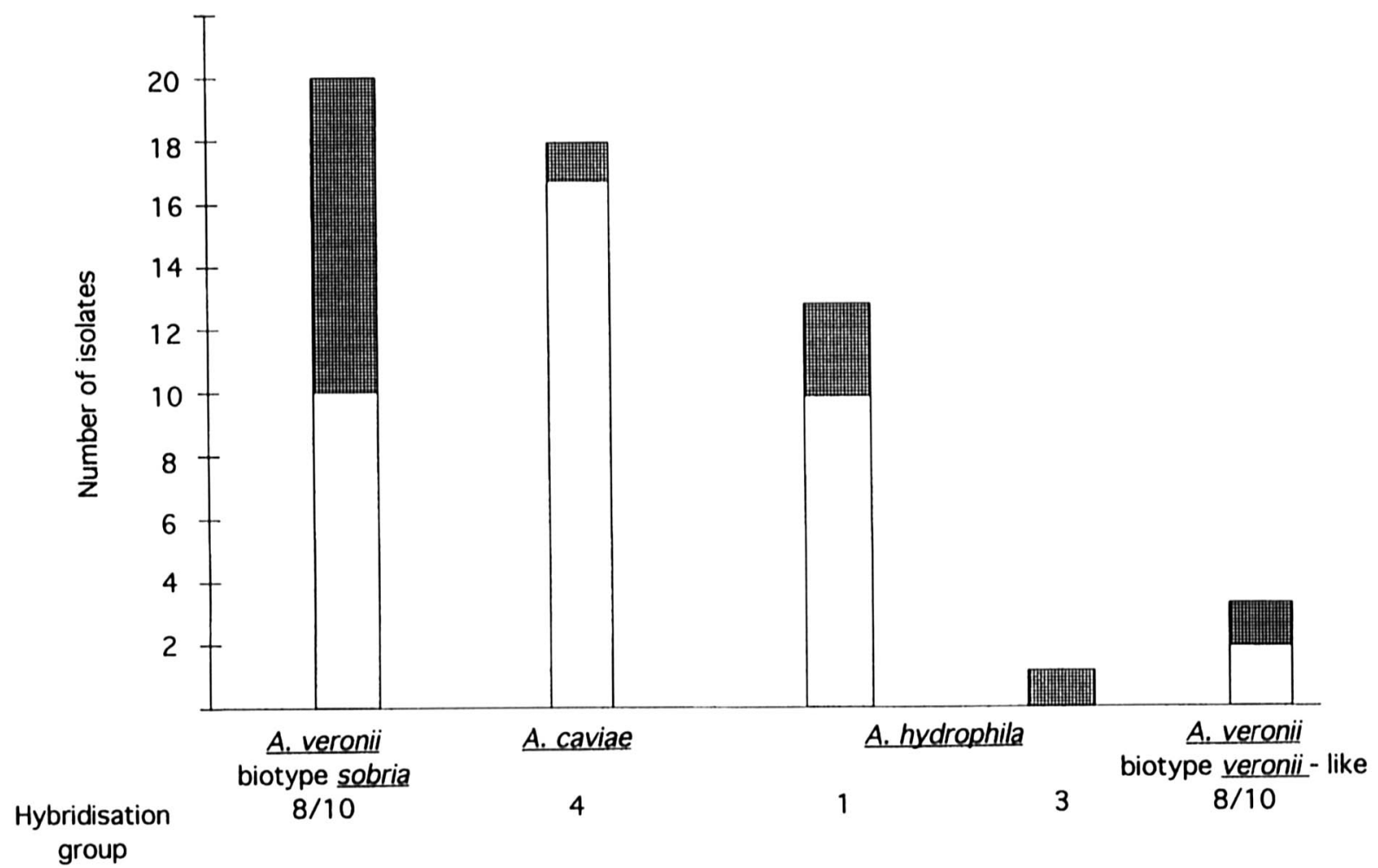

Fig. 3. Aeromonas spp. isolated from diarrhoeal patients living in southern part of Finland with (羁, 16 cases) or without ( $\square$, 39 cases) association to recent travel abroad.

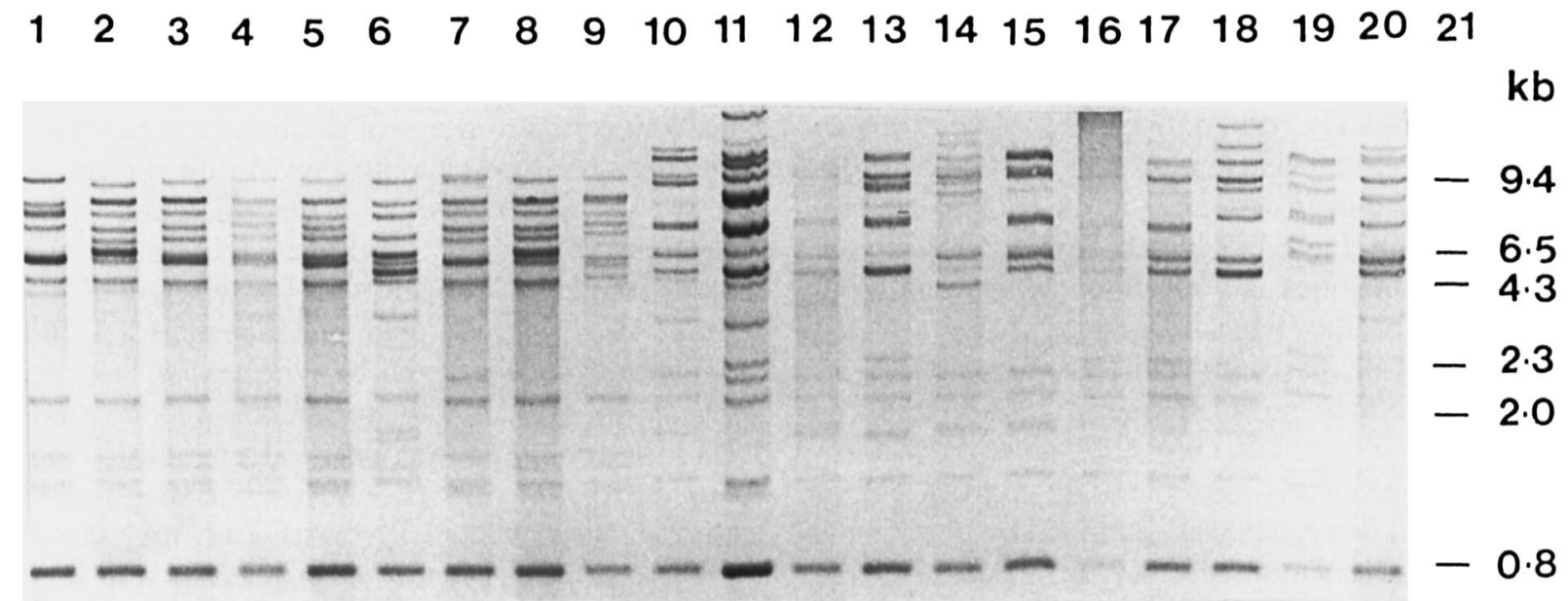

Fig. 4. Ribotyping patterns of representative strains $A$. caviae HG 4 (lanes 1-8) and $A$. veronii biotype sobria $\mathrm{HG} 8 / 10$ (10-19) isolated from tourists with diarrhoea in Morocco. DNA was digested with SmaI and the Southern blot was probed with digoxigenin-labelled cDNA of plasmid pKK 3535 harbouring the $5 S, 16 S$ and 23S rRNA genes. Mol. wt marker ( $\lambda$ DNA HindIII digest; 21) and ribotypes of reference strains of HG 4 (CDC 9083-79, 9) and HG 8/10 (CDC 0337-80, 20).

clear association of particular symptoms with a specific Aeromonas sp. was found.

\section{Species identification and typing of isolates}

The strains were first identified by phenotypic methods as $A$. hydrophila, $A$. caviae, $A$. sobria, $A$. trota or biochemically atypical Aeromonas spp. Ribotyping was used for the identification of genospecies and for subtyping of strains within a genospecies. The genospecies most commonly identified were HG 8/10 ( $A$. veronii biotype sobria and $A$.veronii biotype veroniilike), HG 4 (A. caviae) and $\mathrm{HG} 1$ (A. hydrophila) (fig. 2). Of $10 \mathrm{~A}$. caviae strains, nine belonged to $\mathrm{HG} 4$ and one to $\mathrm{HG}$ 5B. Ribotyping confirmed some atypical strains as $A$. hydrophila $\mathrm{HG} 1$ and some strains resembling $A$. veronii biotype veronii as members of $\mathrm{HG} 8 / 10$. All $A$. veronii biotype veroniilike strains gave positive results in arginine dihydrolase and negative in ornithine decarboxylase tests. In fig. 4, the ribotyping patterns of genomic DNA of some typical strains of the predominating Aeromonas spp. in Morocco, A. caviae HG 4 (lanes 1-8) and A. sobria biotype veronii HG 8/10 (lanes 10-19) digested with SmaI are presented. The mol. wt area (lane 21) of c. $0.8-4 \mathrm{~kb}$ identified a $\mathrm{HG}$ and the mol. wt area of 
c. 4-23 kb was used for the comparison of identity within a HG. ${ }^{18}$ Ribotype patterns of DNA digested with $S m a \mathrm{I}, P s t \mathrm{I}$ or $B g l \mathrm{I}$ indicated that all strains within a genospecies had different ribotypes (results of digests with $P s t \mathrm{I}$ and $B g l \mathrm{I}$ are not shown).

\section{Analysis of stool samples collected in Finland}

In faecal samples collected in Finland, either from people without any history of travelling or from people with a recent travelling history, $A$. veronii biotype sobria, $A$. caviae, $A$. hydrophila and $A$. veronii biotype veronii were isolated from $20,18,14$ and three patients, respectively (fig. 3 ). Half ( 10 of 20 ) of the $A$. veronii biotype sobria isolates were associated with diarrhoea acquired during travelling abroad (Spain, Tanzania, Turkey, Egypt, Kenya or Italy). In four of 14 cases, A. hydrophila was isolated from faecal samples taken after travel to Russia, Estonia or India. Only one of 18 A. caviae isolates was associated with travelling abroad. Ribotypes of the strains were all different within a species and they also differed from the respective ribotypes of the strains isolated from subjects vacationing in Morocco.

\section{Discussion}

At present, about 500000 Finnish people travel yearly to holiday destinations in Mediterranean countries or Asia. Gastrointestinal symptoms, including diarrhoea during or soon after the trip, affect more than 30000 of them. ${ }^{13,20}$ In our extensive study of travellers' diarrhoea among Finns vacationing in Morocco, specific enteropathogens were isolated from c. $60 \%$ of diarrhoeal patients. Aeromonas spp. were the fourth most frequent enteropathogens isolated. ${ }^{13-15}$

In the present study, the role of different species of Aeromonas in diarrhoea was examined by phenotypic and genotypic identification of all strains isolated during two seasons. Although some studies on the aetiology of travellers' diarrhoea report on the isolation of Aeromonas spp. among other enteropathogens, they do not report on the phenospecies or genospecies distribution. ${ }^{4,7,8,21}$ Aeromonas spp. as the sole pathogen were isolated with significantly higher frequency $(5.5 \%)$ from diarrhoeal patients than from subjects without diarrhoea $(1 \cdot 4 \%)$. No seasonal variation in the overall isolation rate of Aeromonas spp. was seen, in contrast to Campylobacter jejuni, which was more common in winter and to enterotoxigenic E. coli (ETEC), which was more common in autumn. ${ }^{13}$ Aeromonas spp. were also isolated from $1 \cdot 1 \%$ of faecal samples from 724 people without diarrhoea. The carriage rate of Aeromonas spp. in the general population is reported to vary from 0.5 to $20 \%$ depending on the population groups studied and the methods used for the detection of the organisms. ${ }^{1,22}$ Symptomatic infections with multiple pathogens are rather common in travellers' diarrhoea. ${ }^{13,21}$ In the present study, Aeromonas spp. were isolated from eight patients ( $36 \%$ ) from a total 22 with diarrhoea, together with either ETEC, $C$. jejuni or Salmonella. One patient had $A$. veronii biotype sobria, $A$. veronii biotype veronii-like and ETEC in his stool sample.

A. caviae (HG 4) and A. veronii biotype sobria (HG $8 / 10$ ) were the predominant species in diarrhoeal patients and they also predominated in the patients who had an Aeromonas spp. as the sole pathogen. The analysis on the distribution of Aeromonas spp. among another group of tourists who had diarrhoea after returning from various developing countries to Finland also suggested that $A$. veronii biotype sobria was associated with travelling. In contrast, $A$. caviae and $A$. hydrophila isolates were not frequently associated with travelling but the infection was acquired in Finland. In Europe and the USA, ${ }^{1,6,22} A$. caviae has been the predominant species identified in diarrhoeal patients, although $A$. hydrophila and $A$. sobria were also isolated. A. hydrophila (HG 1) and $A$. trota (HG 13) were isolated from asymptomatic travellers in Morocco or in association with some other pathogen in symptomatic patients. A. trota is probably a typical species for subtropical or tropical regions because the original $12 \mathrm{~A}$. trota strains described by Carnahan et al. ${ }^{23}$ also were isolated from southern or southeastern Asia.

Identification of Aeromonas spp. to the genospecies level may produce new information on the epidemiology and pathogenesis of aeromonad-associated infections. This study confirmed the results of the earlier studies of Kuijper et al. ${ }^{6}$ Altwegg et al. ${ }^{12}$ and Abbott et al. ${ }^{17}$ on the predominance of HG 8/10 ( $A$. veronii biotype sobria and biotype veronii), HG 4 ( $A$. caviae) and HG 1 (A. hydrophila) in faecal samples. HG 3 (A. hydrophila) was isolated from one diarrhoeal patient (Russia) and HG 5B (A. caviae) from one sample from a patient with diarrhoea (Morocco). HG $13(A$. trota $)$ is probably associated with infections acquired in temperate or tropical areas.

Ribotyping of strains was used to investigate possible epidemiological links between strains. All strains within a HG had a unique ribotype with all three restriction enzymes used. No epidemiological link was found between the strains of a species although they were isolated during the same trip to Morocco or other parts of the world. The wide distribution of ribotypes indicated heterogeneity within a $\mathrm{HG}$ and suggested that a wide variety of strains within a HG can colonise the human intestine. More specific studies are needed to prove the role of Aeromonas spp. in diarrhoea. Aeromonas spp. are common in food and water, ${ }^{24}$ and eating food or drinking water contaminated with Aeromonas strains is not uncommon.

In conclusion, this study has suggested that Aeromonas spp., especially $A$. veronii biotype sobria (HG 8/10) and $A$. caviae (HG 4), were common in 
travellers' diarrhoea although their causative role is not proven. No evidence was shown of a possible epidemiological link between the strains because all the strains within a species had different ribotypes.

\section{References}

1. Altwegg M, Geiss HK. Aeromonas as a human pathogen. $C R C$ Crit Rev Microbiol 1989; 16: 253-286.

2. Borczyk A, McLeod S, Riley G, Lior H. Isolation of Aeromonas species from diarrheal cases in Ontario, Canada. Abstracts of the Fourth International Symposium on Aeromonas and Plesiomonas, 1993. Abstract P-25, 59.

3. DuPont HL, Ericsson DC, Johnson PC, Bitsura JAM, DuPont MW, de la Cabada FJ. Prevention of travelers' diarrhea by the tablet formulation of bismuth subsalicylate. JAMA 1987; 257 : 1347-1350.

4. Echeverria P, Pitarangsi C, Fampokalap B, Vibulbandnitkit S, Boonthai P, Rowe B. A longitudinal study of the prevalence of bacterial enteric pathogens among adults with diarrhea in Bangkok, Thailand. Diagn Microbiol Infect Dis 1983; 1 : 193-204.

5. Holmberg SD, Schell WL, Fanning GR et al. Aeromonas intestinal infections in the United States. Ann Intern Med 1986; 105: 683-689.

6. Kuijper EJ, Bol P, Peeters FM, Steigerwalt AG, Zanen HC, Brenner DJ. Clinical and epidemiologic aspects of members of Aeromonas DNA hybridization groups isolated from human feces. J Clin Microbiol 1989; 27 : 1531-1537.

7. Liesenfeld $O$, Weinke $T$, Hahn $H$. Three-year prevalence of enteropathogenic bacteria in an urban patient population in Germany. Infection 1993; 21 : 101-105.

8. Pitarangsi C, Echeverria $\mathrm{P}$, Whitmire $\mathrm{R}$ et al. Enteropathogenicity of Aeromonas hydrophila and Plesiomonas shigelloides: prevalence among individuals with and without diarrhea in Thailand. Infect Immun 1982; 35: 666-673.

9. Echeverria P, Blacklow NR, Sanford LB, Cukor GG. Travelers' diarrhea among American Peace Corps volunteers in rural Thailand. J Infect Dis 1981 ; 143: 767-771.

10. Janda JM. Recent advances in the study of the taxonomy, pathogenicity, and infectious syndromes associated with the genus Aeromonas. Clin Microbiol Rev 1991;4:397-410.

11. Popoff M. Genus III. Aeromonas. Klyver and Van Niel 1936, $398^{\mathrm{AL}}$. In: Krieg NR, Holt JG (eds) Bergey's Manual of systematic bacteriology, 8th edn, vol 1. Baltimore, Williams and Wilkins Co. 1984: 545-548.

12. Altwegg M, Steigerwalt AG, Altwegg-Bissig R, Luthy-
Hottenstein J, Brenner DJ. Biochemical identification of Aeromonas genospecies isolated from humans. $J$ Clin Microbiol 1990; 28: 258-264.

13. Mattila L, Siitonen A, Kyrönseppä H et al. Seasonal variation in etiology of travelers' diarrhea. J Infect Dis 1993; 165: 385-388.

14. Mattila L, Peltola H, Siitonen A, Kyrönseppä H, Simula I, Kataja M. Short-term treatment of traveler's diarrhea with norfloxacin : a double-blind, placebo-controlled study during two seasons. Clin Infect Dis 1993; 17: 779-782.

15. Peltola H, Siitonen A, Kyrönseppä $\mathrm{H}$ et al. Prevention of travellers' diarrhea by oral B-subunit/whole-cell cholera vaccine. Lancet 1991; 338: 1285-1289.

16. Carnahan AM, Behram S, Joseph SW. Aerokey II: a flexible key for identifying clinical Aeromonas species. $J$ Clin Microbiol 1991; 29: 2843-2849.

17. Abbott SL, Cheung WKW, Kroske-Bystrom S, Malekzadeh T, Janda JM. Identification of Aeromonas strains to the genospecies level in the clinical laboratory. J Clin Microbiol $1990 ; 30$ : 1262-1266.

18. Martinetti Lucchini GL, Altwegg M. rRNA gene restriction patterns as taxonomic tools for the genus Aeromonas. Int $J$ Syst Bacteriol 1992; 42: 384-389.

19. Tarkka E, Åhman H, Siitonen A. Ribotyping as an epidemiologic tool for Escherichia coli. Epidemiol Infect 1994; 112 : 263-274.

20. Peltola H, Kyrönseppä H, Hölsä P. Trips to the South-a health hazard. Morbidity of Finnish travellers. Scand $J$ Infect Dis 1983; 15: 375-381.

21. Black RE. Epidemiology of travelers' diarrhea and relative importance of various pathogens. Rev Infect Dis 1990; 12 Suppl 1: S73-S77.

22. Moyer NP. Clinical significance of Aeromonas species isolated from patients with diarrhea. J Clin Microbiol 1987; 25 : 2044-2048.

23. Carnahan AM, Chakrabotry T, Fanning GR et al. Aeromonas trota sp. nov., an ampicillin-susceptible species isolated from clinical specimens. J Clin Microbiol 1991; 29: 1206-1210.

24. Wadström T, Ljungh $\AA$. Aeromonas and Plesiomonas as foodand waterborne pathogens. Int J Food Microbiol 1991; 12 : 303-311. 